\title{
SYNOPSIS
}

News

$\bullet$

Analysis

- Practice

\section{Disseminating Research}

\section{Providing open access to research, one article at a time}

Advocates of unrestricted public access to scientific research are moving beyond online journals - which are increasingly available only to subscribers - toward encouraging researchers to offer direct access to their published work.

This practice of self-archiving, initially adopted by the technically eager, is now formally encouraged by many academic agencies, research institutions, and even some of the journals that published the articles in the first place.

In January, for example, the Nature Publishing Group started encouraging its authors to self-archive the final version of their articles 6 months postpublication.

"Our emphasis is on recognizing authors, institutions, and funders as stakeholders, and developing our policies so they can do the things they want to do," says David Hoole, head of content licensing and brand marketing for Nature.

Self-archiving is integral to the open access initiative, which aims to make scientific research publications as widely and freely available as possible. A cornerstone statement describing open access, drafted at a meeting of the Open Society Institute in Budapest in 2001, carefully distinguishes selfarchiving from self-publishing.

The Institute, a private foundation established by philanthropist George Soros, supports the peer-review process. However, most peer-reviewed journals are now closed-access. In January, BMf closed access, leaving $C M A \mathcal{F}$ as the sole major medical journal with open online access.

Many journal authors are already self-archiving, according to a 2004 survey conducted by the Open Society Institute and the Joint Information Systems Committee. This independent agency is supported by various UK educational institutions. It indicated that $20 \%-40 \%$ of authors have posted their complete work on a personal or departmental Web site, or some other electronic repository.

Steven Harnad, a Université de Québec à Montréal psychology professor and champion of this initiative, sees self-archiving as part of the research process. "Research funders insist that if they're going to pay you to do research, the results of that research should be made available so other people can use it," he says.

For others, open access is an ethical issue. Dr. James Till, Senior Scientist Emeritus with Toronto's University Health Network says patients and their advocates need access to the latest research. "If you're trying to decide on the best available treatment, 6 months is a huge amount of time," he says, referring to the Nature policy. "Unless authors can self-archive a final, edited, peer-reviewed version as soon as it's been accepted, in an archive for example, it's not open access."

Publishers are obviously concerned that simultaneous selfarchiving of published articles could affect subscriptions, but Till cautions that specific scenarios are far from certain, given the significant upheavals that technology has already brought to publishers. "This is a big set of experiments," he says.

Meanwhile, many institutions are making the technical niceties of self-archiving as painless as possible. St. Andrew's University was among the first to provide a proxy server (http://eprints.st-andrews .ac.uk/proxy_archive.html) to dramatically simplify the steps necessary to self-archive.

More recently, the University

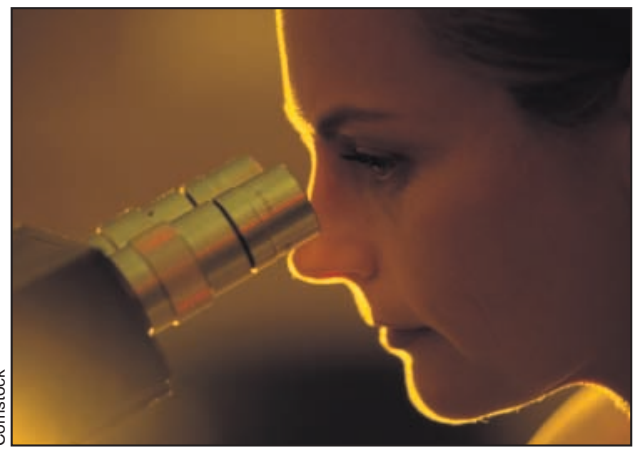

Researchers are increasingly self-archiving to ensure that their work is available.

of Toronto launched T-Space, a centralized server. Participants will retain their individual copyrights and the university will assume responsibility for preserving and distributing articles.

Till notes that the selfarchiving movement will also have to cope with the distinction between strictly vetted scientific publications and documents that have received much less rigorous treatment. "There will still be a credible literature and a grey literature, but they're going to get more blurred."- Tim Lougheed, Ottawa 